\title{
Exploring users' experience with e-reading devices
}

\author{
Chrysoula Gatsou \\ Faculty of Fine Arts and Design, \\ TEI of Athens \\ Athens, Greece \\ Email: cgatsou@teiath.gr
}

\author{
Anastasios Politis \\ Faculty of Fine Arts and Design, \\ TEI of Athens \\ Athens, Greece \\ Email: politisresearch@techlink.gr
}

\author{
Dimitrios Zevgolis \\ School of Applied Arts \\ Hellenic Open University, \\ Patra, Greece \\ Email: zevgolis@eap.gr
}

\begin{abstract}
New e-book readers and multifunctional mobile tablet devices are currently emerging, so bringing about a transition from printed to the electronic books. It is important to learn how usable these mobile devices are, by testing them on real users from various backgrounds. The paper presents a study which explores the perceived usability of two electronic reading devices, one dedicated reader and one multifunctional device. More specifically, the study employs eight tasks which users were required to complete within a specific time with two devices. Our results show that users functioned better on the multifunctional device in terms of performance measures, such as navigation, task difficulty and satisfaction.
\end{abstract}

\section{INTRODUCTION}

E lectronic reading devices, including e-readers and tablet computers, are becoming popular so rapidly today, that it is vital to understand how the users themselves perceive the usability of such devices. An e-reader is designed for displaying electronic books, magazines, and periodicals. Various e-readers use various formats. For example, ibooks are produced for the iPad, whilst AZW, TXT and KF8 formats are mostly used by the Kindle. E-books are frequently available in PDF format, which is common for popular computer operating systems.

New opportunities for e-reading appeared, when lighter devices with better screens, such as the Amazon Kindle, appeared in late 2000 and the content available to devices increased at the same time. A vital question is why one should use an electronic reader, when one can use a netbook, tablet or a smart phone. The fundamental advantage of the electronic reader lies in its display. Thanks to the materials from which the display is manufactured, its appearance resembles that of paper, which means that the user does not have to strain his or her eyes when reading. Making objects more usable and accessible is part of the larger discipline of User-Centered Design, which employs various methods and techniques [1]. Usability testing is a method employed to evaluate a product by testing it on representative users. Greenberg and Buxton point out that "Usability evaluation is valuable for many situations, as it often helps validate both research ideas and products at varying stages in its lifecycle" [2]. The purpose of our study was to explore user experience with two e-reading devices. One was dedicated e-reader device, the Cybook Odyssey and the other was a multifunctional device, the Apple iPad. The main criterion for selecting these mobile devices was their availability on the Greek market at the time, November 2013. Despite the best efforts of designers, new technologies often fail to meet basic human needs and desires [3].

We start our paper with a review of the literature, which establishes the theoretical background to our study. We then describe the research methodology employed, discuss the results and offer some conclusions.

\section{BACKGROUND}

\section{A. E-readers}

An e-reader, also called an e-book reader or e-book device, is a mobile electronic device designed primarily for the purpose of reading digital e-books. New opportunities for e-reading emerged when new lighter devices, such as the Amazon Kindle, that had better screens, appeared at the end of 2000 and the available content for devices increased at the same time. E-readers reproduces the appearance of a printed book.

Thus an e-reader should ideally offer readability, be able to host extensive texts, be portable, allow one to read anywhere and possess a long-lasting battery. It should also offer the ability to create bookmarks, to add notes on the book and to highlight passages as desired. The most important part of an e - reader is the screen. Unlike the majority of displays with which we interact on daily basis, paper is a reflective medium. As Zehner notes, a reflective display has an inherent advantage in terms of readability, because the brightness of the display naturally adapts to the ambient lighting conditions [4]. E-paper displays are expected to provide the user with a more paper-like reading experience that does not cause eye strain and that possess the contrast and reflection of real paper [5]. 


\section{B. E-Ink technology}

E-Ink is a bistable display technology that creates a nearpaper-like reading experience and requires minimal battery power [6]. Electronic ink is made up of millions of tiny microcapsules only 100 microns in width. Every microcapsule contains positively-charged white particles and negatively-charged black particles suspended in a clear fluid. When a positive or negative electric field is applied, the chips will either rise to the top or be pulled to the bottom, where they become visible to the viewer [7]. This makes the surface appear either white or black at the spot in question. Patterns of white and dark can then be created to form words and sentences (Fig.1). E-Ink displays do not need any background lighting and are easy to read, even in direct sunlight. Although E Ink technology devices require energy for turning pages, they do not consume much battery power. This means that a device, when fully charged, can be used for several thousand pages or several weeks.

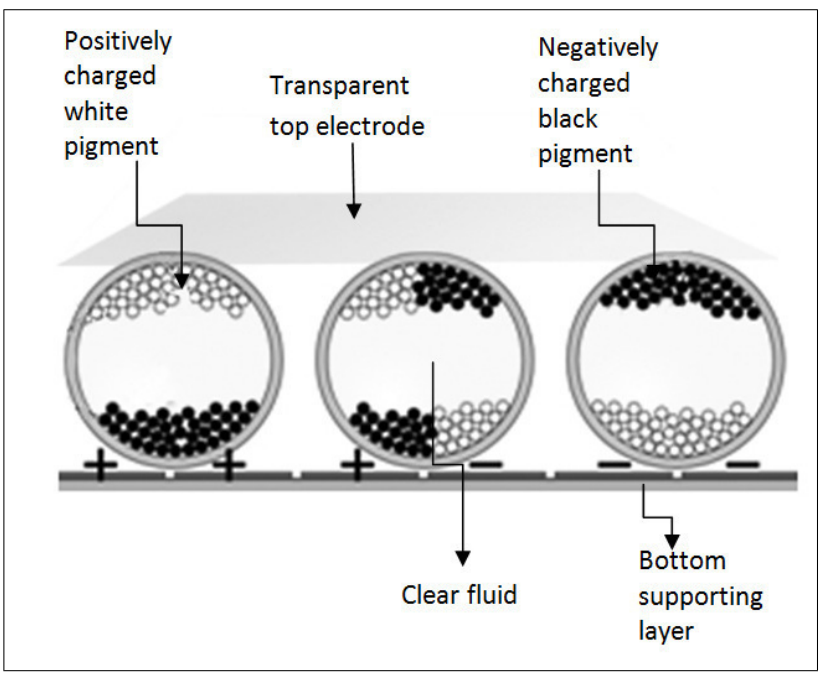

Fig. 1 Scheme of electronic ink technology.

\section{C.iPad}

The iPad is a tablet computer. Its basic technology differs from that of dedicated e-readers, in that it has a colour screen which does not employ the eye-friendly E-Ink technology and it is multi-functional. The iPad has been found to compete well with dedicated e-readers. Probably the most comprehensive iPad usability studies are those carried out by by Nielsen and Budiu in 2010 and 2011 [8,9]. Their findings are summarized below:

Read-tap asymmetry

Content was large enough to read, but too small to tap.

Accidental activation

This was a particular problem in apps lacking a back button.

Too small touchable areas too close together

This lead to accidental activation.

Users disliked typing

They thus avoided the registration process
Splash screens

A compulsory introduction screen bothers users.

Information squeezed into too small areas

This made the content harder to perceive and manipulate.

Too much navigation

The large number of navigation options gives one less space.

\section{D.E-readers and Usability}

Nielsen did a within-subjects study employing 32 competent adult readers. The text was a Hemingway short story in several formats, namely printed book, personal computer, iPad and Kindle. The iPad gave a $6.2 \%$ lower reading speed than the printed book, whereas the Kindle gave a speed $10.7 \%$ slower than print [10]. However, the difference between the two devices was not statistically significant, because of the fairly high variability of the data.

Clark et al., reported that 36 Kindle users at the University of Texas thought that the limited content availability, the inconsistent pricing of titles, poor graphics resolution and other functions were barriers to the wider acceptance and use of the device [11].

\section{B. Usability testing}

The term "usability" is frequently employed in the field of human-computer interaction (HCI). Nielsen describes usability as an issue related to the broader issue of acceptability [12]. In his view, "Usability is a quality attribute that assesses how easy user interfaces are to use". Usability is a significant part of the user experience and therefore of user satisfaction. A formal definition of usability is given in the ISO standard 9241-11: “...the extent to which a product can be used by specified users to achieve specified goals with effectiveness, efficiency and satisfaction, in a specified context of use". Effectiveness is defined as the accuracy and completeness with which users achieve specified goals and efficiency as the resources expended in relation to the accuracy and completeness with which users achieve goals. Satisfaction is defined as the freedom from discomfort, and positive attitude to the use of the product, whilst the context of use is defined as users, tasks, equipment and the physical and social environments in which a product is used [13].

Usability testing is a method employed in user-centered design to evaluate product design by testing it on representative users. Such users thus yield quantitative and qualitative data in that they are real users performing real tasks [14].

Dumas \& Redish argue that usability testing is a " $a$ systematic way of observing actual users trying out a product and collecting information about the specific ways in which the product is easy or difficult for them " [15].

\section{Research Methodology}

To examine how users conceptualize interaction with ereaders, we created a user test involving two e-reading devices. We compare one dedicated e-reader with one multifunctional device (Fig.2). 

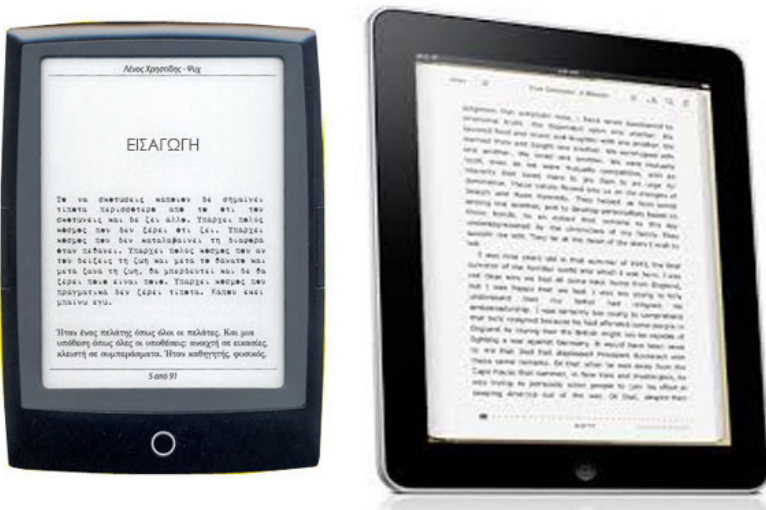

Fig. 2 The two mobile devices compared in the study: The Cybook Odyssey and the Apple iPad.

Nielsen [16] argues that five participants will discover $80 \%$ of the problems in a system. In any case, a small quantity of users, that is, generally fewer than 10 subjects, is sufficient, for any formative evaluation of usability [17]. On the other hand, Spool and Schroeder [18] state that five users identified only about $35 \%$ of the problems in a website. The research by Turner et al. implies that a group size of seven may be optimal, even when the study is fairly complex [19].

According to Sauro and Lewis "the most important thing in user research, whether the data are qualitative or quantitative, is that the sample of users you measure represents the population about which you intend to make statements" [20].

\section{A. Participants}

Our session was designed specifically to include a representative pool of the potential users of e-readers. Twelve participants $(\mathrm{N}=12)$ aged between 18 - 65 (mean age $=36.08, \mathrm{SD}=14.47$, years), seven of whom were males and five females, participated in the session. Using either a skilled participant or an under-qualified one will bias the outcomes of usability testing. All participants were novices as regards e-reading devices, but were fond of reading. On the other hand, all of them had used a digital device (e.g. PC or mobile phone) prior to this study, to read news, information or academic content online. The participants received short instructions on how to turn their device on and off, but were not instructed in how to operate it. This was designed to test the usability of the devices and to examine how intuitive the interface was for the participants. Participants did not suffer from any visual or cognitive impairment and were educated to at least high school level. Participants gave written informed consent prior to participation.

\section{B. Material}

Two mobile devices, the Apple iPad, a multifunctional ereader and the Cybook Odyssey, a dedicated e-reader, were compared in the study. Devices were chosen on grounds of anticipated availability on the Greek market. A Panasonic
TABLE I.

TECHNICAL SPECIFICATIONS OF THE TWO COMPARED DEVICES.

\begin{tabular}{|l|l|l|}
\hline $\begin{array}{l}\text { Thechnical Specifica- } \\
\text { tions }\end{array}$ & Cybook Odyssey & $\begin{array}{l}\text { Apple iPad (3' } \\
\text { generation) }\end{array}$ \\
\hline Intro year & 2013 & 2012 \\
\hline Display size & $6^{\prime \prime}$ & $9.7^{\prime \prime}$ \\
\hline Display type & I-ink HD & LCD screen \\
\hline Rresolution & $758 \times 1024$ & $2048 \times 1536$ \\
\hline Weight & $180 \mathrm{~g}$ & $652 \mathrm{~g}$ \\
\hline Touch screen & Multi touch & Multi touch \\
\hline Memory & $\begin{array}{l}2 \mathrm{~GB} \text { iNAND+ } \\
\text { MicroSDHC up to } \\
32 \mathrm{~GB}\end{array}$ & $16 \mathrm{~GB}$ \\
\hline $\begin{array}{l}\text { Content ebook } \\
\text { formats }\end{array}$ & $\begin{array}{l}\text { EPUB, PDF, Adobe } \\
\text { DRM, HTML, TXT, } \\
\text { FB2 }\end{array}$ & $\begin{array}{l}\text { Ibooks, } \\
\text { PDF ePub, }\end{array}$ \\
\hline $\begin{array}{l}\text { Content picture } \\
\text { formats }\end{array}$ & $\begin{array}{l}\text { JPEG, PNG, GIF, } \\
\text { BMP, ICO, TIF, PSD }\end{array}$ & \begin{tabular}{l} 
JPEG, GIF, TIF, \\
\hline BSD
\end{tabular} \\
\hline Battery life & Up two weeeks & Up to 10 hours \\
\hline
\end{tabular}

HDC-SD40 digital camera was used to create a complete record of all user interactions with the e-readers. Technical specifications for the mobile devices are provided in Table I.

\section{User Tasks}

For the usability test, the participants were required to read a segment of the text from an e-book on Greek mythology on the two e- reading devices and to complete eight tasks given in Table II. The tasks were chosen as being representative and as covering as many as possible of the features of the e-reading devices. Task success (whether or not a participant successfully completed a task) was recorded. Participants were allowed up to two minutes to complete each task.

TABLE II

PARTICIPANTS TASKS

\begin{tabular}{|l|l|}
\hline Tasks & Task Description \\
\hline Task 1 & Open the book "Mythology" \\
\hline Task 2 & Go to page 26 \\
\hline Task 3 & Change the page to landscape format \\
\hline Task 4 & Highlight the first two sentences of the page \\
\hline Task 5 & Delete the highlighted sentences \\
\hline Task 6 & Make a note of the first paragraph of the page \\
\hline Task 7 & Increase the font size \\
\hline Task 8 & Add bookmark \\
\hline
\end{tabular}

\section{User Performance}

User performance was recorded in terms of the effectiveness, efficiency and ease of use of e-reading 
devices. In order to evaluate task effectiveness, we measured the percentage of tasks successfully completed within the time limit. Task completion time refers to the time needed to accomplish the task. To evaluate efficiency, we recorded the time needed to process a task. To measure user satisfaction, we asked users to complete a post-test questionnaire SUS (system usability scale). A SUS questionnaire gives ten statements regarding different aspects of usability. Users mark their agreement with the statements on a five-point Likert scale.

\section{E. Post-test Questionnaire}

The aim in administering a written questionnaire after the test (post-test questionnaire) is to record participants' preference, in order to identify any potential problems with the product. Information collected usually includes opinions and feelings regarding any difficulties encountered in using the product. Our questionnaire was based on the System Usability Scale (SUS) developed by Brooke [21], since this is the most precise type of questionnaire for a small number of participants, as is shown by Tullis and Stetson's study [22]. SUS employs a "quick and dirty" approach in evaluating the overall subjective usability of a system (Appendix A). While the SUS was originally intended to be used for measuring perceived usability, i.e. measuring a single dimension, recent research shows that it provides an overall measure of satisfaction of the system [22],[23],[24]. In addition to these advantages over other systems, the SUS is a powerful and multifunctional instrument [25].

\section{F. Test protocol}

Participation in the study lasted approximately 40 minutes for each participant and was conducted in an isolated room in our Faculty. Participation consisted of the series of tasks mentioned above. Participants were informed for the process of the test and all participants were tested individually.

After being welcomed by the experimenter, participants were told that they were to take part in a usability test and were to interact with two e-reading devices. Participants were reminded to note the instruction for gestures on the desk on their left. In addition participants gave their permission to be recorded on video. Subsequently participants completed our eight tasks. Finally there was a question about what readers considered the most important features in eReaders

\section{RESUlTS AND DisCUSSION}

The main factors to be examined when testing usability are effectiveness, efficiency and user satisfaction. Effectiveness refers to how "well" a system does what it supposed to do. In order to evaluate task effectiveness, we measured the percentage of steps successfully negotiated within the time limit (2min). Efficiency refers to how quickly a system supports the user in what he wants to do. To evaluate efficiency, we recorded the time needed to process the task. Satisfaction refers to the subjective view of the system on the part of the user [1]. Qualitative and quantitative data were collected from each participant.
Qualitative data included the participants' verbal protocol as recorded in video recording.

Problems of usability were identified and categorized. We also collected comments on e-reading devices and preference data and evaluations in the form of the SUS data questionnaire completed by the users after the test. Any user action that did not lead to the successful completion of a task we defined as error.

TABLE III

TASKS COMPLETION RATES

\begin{tabular}{|l|c|c|}
\hline & Cybook & iPad \\
\hline \multirow{3}{*}{ Task1 } & $11 / 12$ & $12 / 12$ \\
\cline { 2 - 3 } & $\mathbf{9 1 \%}$ & $\mathbf{1 0 0 \%}$ \\
\hline \multirow{3}{*}{ Task2 } & $9 / 12$ & $11 / 12$ \\
\cline { 2 - 3 } & $\mathbf{7 5 \%}$ & $\mathbf{9 1 \%}$ \\
\hline \multirow{3}{*}{ Task3 } & $8 / 12$ & $9 / 12$ \\
\cline { 2 - 3 } & $\mathbf{6 6 \%}$ & $\mathbf{7 5 \%}$ \\
\hline \multirow{3}{*}{ Task5 } & $7 / 12$ & $8 / 12$ \\
\cline { 2 - 3 } & $\mathbf{5 8 \%}$ & $\mathbf{6 6 \%}$ \\
\hline \multirow{3}{*}{ Task6 } & $7 / 12$ & $11 / 12$ \\
\cline { 2 - 3 } & $\mathbf{5 8 \%}$ & $\mathbf{9 1 \%}$ \\
\hline \multirow{3}{*}{ Task7 } & $2 / 12$ & $7 / 12$ \\
\cline { 2 - 3 } & $\mathbf{1 6 . 7 \%}$ & $\mathbf{5 8 \%}$ \\
\hline \multirow{3}{*}{ Task8 } & $9 / 12$ & $10 / 12$ \\
\cline { 2 - 3 } & $\mathbf{7 5 \%}$ & $\mathbf{8 3 . 3} \%$ \\
\cline { 2 - 3 } & $10 / 12$ & $11 / 12$ \\
\hline
\end{tabular}

\section{A. Effectiveness.}

The percentage of users that manage to complete a task successfully thus becomes a measure of the effectiveness of the design. The number of errors made on the way to completing a task is an example of a performance measure [1],[12].

Errors were classified into two main categories, navigation errors and comprehension errors. Navigation errors occurred when partcipants did not move as expected. Comprehension errors occured when participants did not understand the design of the interface. (Table IV).

TABLE IV

TYPES OF ERRORS BY E-READER DEVICE

\begin{tabular}{|l|c|c|}
\hline Type of error & Cybook & iPad \\
\hline Navigation & 3 & 4 \\
\hline Comprehension & 5 & 3 \\
\hline Total & 8 & 7 \\
\hline
\end{tabular}

\section{B. Efficiency - Task Completion Time}

Efficiency is a measure that is highly dependent on the time spent on completing the task. We recorded the total amount of time required to complete each task on mobile devices. Table V shows information on the mean time spent 
by the participants. The results thus indicate that participants spent more time on task completion when using the Cybook.

TABLE V

AVERAGE TIME IN SECONDS FOR COMPLETING ALL GIVEN TASKS

\begin{tabular}{|c|c|c|c|}
\hline Tasks & Task Description & Cybook & iPad \\
\hline Task 1 & Open the book "Mythology" & 29,7 & 24,2 \\
\hline Task 2 & Go to page 26 & 63,7 & 48,3 \\
\hline Task 3 & $\begin{array}{l}\text { Make a note of the first } \\
\text { paragraph of the page }\end{array}$ & 78,2 & 65,1 \\
\hline Task 4 & $\begin{array}{l}\text { Highlight the first two sentences } \\
\text { of the page }\end{array}$ & 67,3 & 52,6 \\
\hline Task 5 & Delete the highlighted sentences & 42,3 & 38,2 \\
\hline Task 6 & $\begin{array}{l}\text { Change the page to landscape } \\
\text { format }\end{array}$ & 27,2 & 14,1 \\
\hline Task 7 & Increase the font size & 35,6 & 17,2 \\
\hline \multirow[t]{3}{*}{ Task 8} & Add bookmark & 48,7 & 29,7 \\
\hline & Average Time & 49,1 & 36,2 \\
\hline & Standard Deviation & 18,8 & 18,1 \\
\hline
\end{tabular}

However with the respect of the amount of time that participants spend on Cybook was higher than iPad. The expectation was, however, that participants would interact more efficiently with a dedicated e-reader than with a multifunctional device when reading a book (Fig.3).

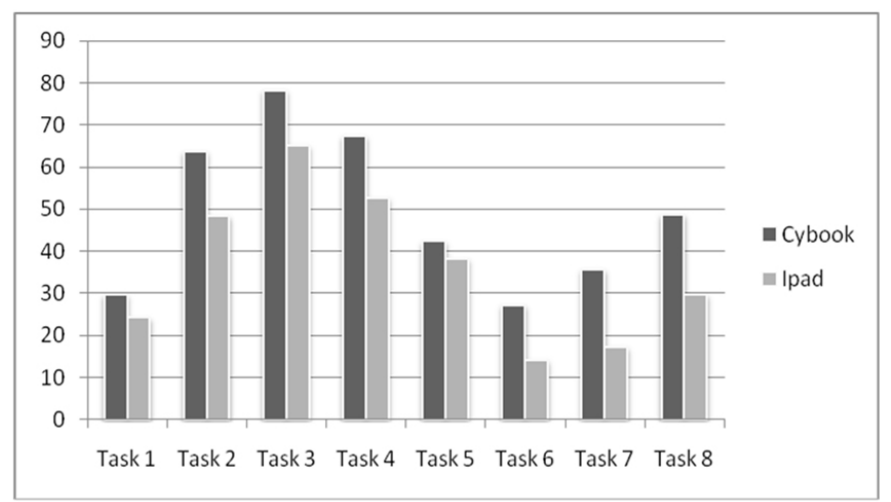

Fig.3 Task completion time per e-reader device.

\section{User satisfaction}

We. are aware that time-on-task measures can be useful for collecting data on the efficiency of a system. On the other hand, such data does not give any information on overall satisfaction on the part of the user. User satisfaction may be an important factor in motivating people to use a product and may affect user performance. Thus, as a final point, we decided participants should complete the System Usability Scale (SUS) questionnaire which has ten item attitude Likert-scale which measures the view of subjective assessments of usability and explore users' experiences with the two mobile devices. A crucial feature of the SUS lies in the fact that asks the user to evaluate the system as a whole, rather than specific aspects.

All 10 questionnaire statements having been processed, the overall SUS score for each prototype is that given in Table VI. To calculate the SUS score, first we summed the score contributions of items 1, 3, 5, 7 and 9 (Appendix A). The score contribution of these items are their scale position minus one. We then summed the score contributions of the other items: five minus their scale position. Finally, we multiplied the sum of the scores by 2.5 , to obtain the overall score with a range between 0 to 100 .

The study results showed the overall level of satisfaction. Sauro reports that a mean value over 74 is level $B$, value above 80.3 is level A [25]. An average value of below 51 is level $\mathrm{F}$ (fail). The iPad, which was given an average value of 79.3, is to be placed on level B, and Cybook, with an average value of 70.8, level $\mathrm{B}$. It can be remarkable to notice that none of the e-Readers had an extremely high satisfaction score, meaning that users preferences were ambiguous.

TABLE VI

OVERALL SUS SCORE

\begin{tabular}{|l|l|l|}
\hline Participants & Cybook & iPad \\
\hline P1 & 80.0 & 80.0 \\
\hline P2 & 70.0 & 87.5 \\
\hline P3 & 82.5 & 90.0 \\
\hline P4 & 77.5 & 90.0 \\
\hline P5 & 55.0 & 82.5 \\
\hline P6 & 70.0 & 77.5 \\
\hline P7 & 75.0 & 65.0 \\
\hline P8 & 70.0 & 75.0 \\
\hline P9 & 72.5 & 82.5 \\
\hline P10 & 70.0 & 82.5 \\
\hline P11 & 72.5 & 70.0 \\
\hline P12 & 55.0 & 70.0 \\
\hline Mean & $\mathbf{7 0 . 8}$ & $\mathbf{7 9 . 3}$ \\
\hline
\end{tabular}

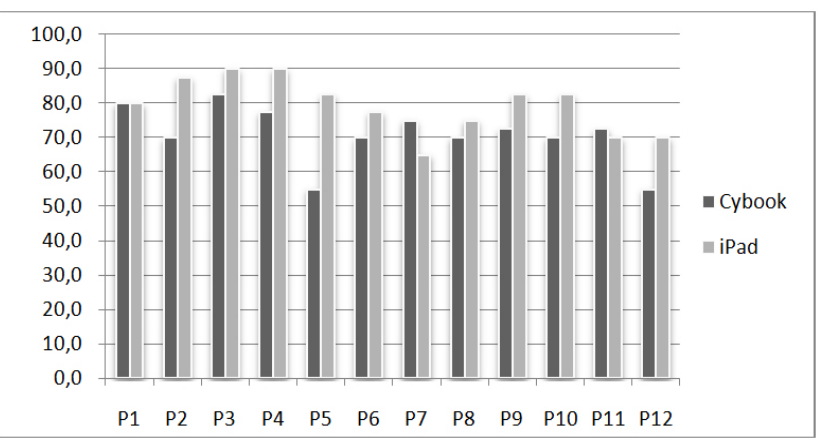

Fig.4 Overall SUS score.

\section{Overall user experience}

Overall users liked the process and regarded their interaction with the devices positively. Nevertheless, in some cases, the participants were apprehensive. Uncertain 
in their selections, they demanded greater confirmation and reassurance about the actions they were to take. In such cases, it is important for the researcher to motivate participants, encouraging them discreetly to investigate alternative directions, while simultaneously recording any mistakes made. Participants reported that the task in which one had to make a note was difficult to perform on the Cybook, as the keypad was complicated in comparison to that of the iPad.

Overall, participants had a preference for the iPad when highlighting and making notes. Additionally, the ability to change font size on the Cybook means that the device uses location numbers, rather than page numbers. The following conclusions can be drawn from the results derived from our group of participants, but one should avoid making any generalizations based on them. (Fig.4)

Participants complained of

- Poor page navigation

- Difficulty in turning the page

- Slowness in adapting to non-linear reading and

- The environment

On the other hand, participants reported that :

- In the case of the dedicated device (the Cybook), the menu allowed users to find some functions easily,

- older participants liked the ability to adjust font size,

- the portability and lightness of the devices was appreciated and that,

- when users read a narrative on an e-book sequentially from beginning to end, they found e-ink technology more friendly than the corresponding technology employed on the other device ( $i P a d)$.

\section{Limitations}

The results of the study should not be generalized to all e -readers mobile devices. The small sample size $(\mathrm{n}=12)$ limited the ability to acquire a more comprehensive view of the effects of various reading formats. Some e-readers are very similar in format to traditional print books. Reading on a very small screen device, however, like reading on a smartphone or online reading in a personal computer, with its links, multiple pages, and sometimes distracting graphics, raises various issues [26].

Another important reason was that participants read a narrative book, rather than a text offering information.

\section{V.CONCLUSION}

The aim of our study was to explore user experience with two e-reading devices. One was a dedicated e-reader device, the Cybook Odyssey and the other was a multifunctional device, the Apple iPad. We tested our empirical methodology on twelve individuals, all of them novices in terms of e-reader use. The goal of our user study was to gain knowledge on the readability and usability of two different e-readers devices in a specific context. As a consequence of the small sample size $(n=12)$, we evaluated our data on the basis of descriptive statistics. Eight tasks were selected in order to elicit user experience.
The results of the study show that both in terms of usabillity and overall impression, the iPad was the preferred device. This was somewhat surprising, as the lightness, long battery life and portability of the Cybook was greatly liked by the participants in the study. Additionally the testing material was a black and white book on Greek mythology and not a multi color magazine which is better for iPad use.

However, we feel that our paper, which focuses more on the users and their cognitive abilities, offers a new insight into how users perform tasks with e-readers devices and conveys their overall impressions. Long battery life and portability are advantages for any use, but the inability to facilitate easy browsing and navigation make the devices slow to use for any non-linear reading. In addition, from users' comments there emerged additional issues regarding digital rights management (DRM), and storage which should be explored in future studies. We believe that successful ereading use depends on the integration between reading device, content providers and service platform.

\section{APPENDIX}

Appendix A System Usability Scale

\begin{tabular}{|c|c|c|c|c|c|}
\hline & \multicolumn{3}{|c|}{$\begin{array}{l}\text { Strongly } \\
\text { agree }\end{array}$} & \multicolumn{2}{|c|}{$\begin{array}{l}\text { Strongly } \\
\text { disagree }\end{array}$} \\
\hline $\begin{array}{l}\text { 1. I think I would like to use this } \\
\text { device frequently }\end{array}$ & 1 & 2 & 3 & 4 & 5 \\
\hline $\begin{array}{l}\text { 2. I found the device } \\
\text { unnecessarily complex. }\end{array}$ & 1 & 2 & 3 & 4 & 5 \\
\hline $\begin{array}{l}\text { 3. I thought the device was } \\
\text { easy to use. }\end{array}$ & 1 & 2 & 3 & 4 & 5 \\
\hline $\begin{array}{l}\text { 4. I think that I would need the } \\
\text { support of a technical person to } \\
\text { be able to use this device. }\end{array}$ & 1 & 2 & 3 & 4 & 5 \\
\hline $\begin{array}{l}\text { 5. I found the various functions } \\
\text { in this device were well } \\
\text { integrated. }\end{array}$ & 1 & 2 & 3 & 4 & 5 \\
\hline $\begin{array}{l}\text { 6. I thought there was too much } \\
\text { inconsistency in this device. }\end{array}$ & 1 & 2 & 3 & 4 & 5 \\
\hline $\begin{array}{l}\text { 7. I would imagine that most } \\
\text { people would learn to use this } \\
\text { device very quickly. }\end{array}$ & 1 & 2 & 3 & 4 & 5 \\
\hline $\begin{array}{l}\text { 8. I found the device very } \\
\text { cumbersome to use. }\end{array}$ & 1 & 2 & 3 & 4 & 5 \\
\hline $\begin{array}{l}\text { 9. I felt very confident using the } \\
\text { device. }\end{array}$ & 1 & 2 & 3 & 4 & 5 \\
\hline $\begin{array}{l}10 . \text { I need to learn a lot of } \\
\text { things before I could get going } \\
\text { with this device. }\end{array}$ & 1 & 2 & 3 & 4 & 5 \\
\hline
\end{tabular}




\section{ACKNOWLEDGMENT}

We express our gratitude to the participants, who enthusiastically gave their time to allow us to understand the value of their experiences.

\section{REFERENCES}

[1] J.Rubin, and D. Chisnell, Handbook of Usability Testing: How to Plan, Design and Conduct Effective Tests (2nd Ed.). Indianapolis, IN Wiley Publishing, 2008.

[2] S. Greenberg and B. Buxton, Usability evaluation considered harmful (some of the time). Proceeding of the Twenty-Sixth Annual SIGCHI Conference on Human factors in Computing Systems, Florence, 2008, 111-120.

[3] M. Hassenzahl, The effect of perceived hedonic quality on product appealingness. International Journal of Human-Computer Interaction, 13(4), pp. 479-497, 2002.

[4] R. Zehner, "Electronic Paper Displays." In Mobile Displays: Technology and Applications (eds A. K. Bhowmik, Z. Li and P. J. Bos), John Wiley \& Sons, Ltd, Chichester, UK, 2008.

[5] H. Heikkil 圆a. eReading User Experiences: eBook Devices, Reading Software \& Contents. Technical Report 54, NextMedia, 2011.

[6] DeJean, D. "The future of e-paper: The Kindle is only the beginning."Computerworld, June, 1, 2008. Retrieved from http://www.computerworld.com/article/2535080/ Accessed on $12 / 4 / 2014$

[7] E Ink: http://www.eink.com. Accessed on 12 April 2014.

[8] R. Budiu and J. Nielsen. "Usability of iPad Apps andWebsites: 1st edition". Technical report, 2010.

[9] R. Budiu and J. Nielsen. "Usability of iPad Apps and Websites: 2nd edition”. Technical report, 2011.

[10] J. Nielsen, "iPad and Kindle reading speeds", 2010 Retrieved from http://www.useit.com/alertbox/ipad-kindle-reading.html

[11] D. T. Clark, S. P. Goodwin, T. Samuelson, C.Coker, "A qualitative assessment of the Kindle e-book reader: results from initial focus groups", Performance Measurement and Metrics, Vol. 9 Iss: 2, pp.118 $-129,2008$.

[12] J. Nielsen and R. L. Mack. Usability inspection methods. Wiley, New York, NY, USA, 1994.

[13] ISO 9241-11 Ergonomic requirements for office work with visua display terminals (VDTs)-Part 11, Guidance on usability, ISO, 1998.
[14] A.Cooper, R. Reimann, and D. Cronin, About Face 3: The Essentials of User Interface Design. John Wiley \& Sons, Inc. 2007.

[15] J.S Dumas and J.C Redish, A Practical Guide to Usability Testing (revised Ed.). Portland, Oregon: Intellect Books, 1999.

[16] J.Nielsen, "Why You Only Need to Test With 5 Users". Jakob Nielsen's Alertbox, March 19, 2000.

[17] H. Petrie and N. Bevan. The evaluation of accessibility, usability and user experience In: The Universal Access Handbook, C Stepanidis (ed), CRC Press, pp 299-315, 2009.

[18] J. Spool and W. Schroeder " Testing web sites: Five users is nowhere near enough", In: Proceedings of the Conference extended abstracts on Human Factors in Computing Systems, CHI'2001. New York: ACM Press, 2001

[19] C. W. Turner, J. R. Lewis, and J. Nielsen, "Determining usability test sample size". In W. Karwowski (ed.), International Encyclopedia of Ergonomics and Human Factors Boca Raton, FL: CRC Press, 2006, pp. 3084-3088, 2006.

[20] J. Sauro and J.R. Lewis, Quantifying the user experience: Practical statistics for user research. Burlington, MA: Morgan Kaufmann, 2012.

[21] J. Brooke, SUS: a "quick and dirty" usability scale. In P. W. Jordan, B. Thomas, B. A. Weerdmeester, \& A. L. McClelland (Eds.), Usability Evaluation in Industry (S. 189 -194). London: Taylor and Francis, 1996.

[22] T. Tullis, and J. Stetson, "A comparison of questionnaires for assessing website usability," In Proc. of the Usability Professionals Association (UPA), pp. 7-11, 2004.

[23] J. R. Lewis, and J. Sauro, "The factor structure of the system usability scale", Proc. Human Computer Interaction International Conference (HCII 2009), San Diego, CA, pp. 94-103, 2009.

[24] J. Sauro, "Does prior experience affect perceptions of usability?" Available:http://www.measuringusability.com/blog/priorexposure.php, January 19, 2011 [Nov.15, 2012]

[25] J. Sauro, A practical guide to the System Usability Scale (SUS): Background, benchmarks \& best practices. Denver, CO: Measuring Usability LLC, 2011.

[26] Leu, D. J., McVerry, J. G., O’Byrne, W.I ., Kiili, C., Zawilinski, L., Everett-Cacopardo, H., \& Forzani, E.. The new literacies of online reading comprehension: Expanding the literacy and learning curriculum. Journal of Adolescent \& Adult Literacy, 55, 5-14, 2011.

[27] P Lam, SL Lam, J Lam, C McNaught, "Usability and usefulness of eBooks on PPCs: How students' opinions vary over time,".Australian Journal of Educational Technology, 25(1), pp. 30-44, 2009. 